\title{
CORRECTIONS
}

\section{Management of urinary incontinence in women: summary of updated NICE guidance}

In this Practice article by Antony Smith and colleagues (BMJ 2013;347:f5170, doi:10.1136/bmj.f5170), the section on use of botulinum toxin A for treating overactive bladder wrongly stated that botulinum toxin type A did not have a UK marketing authorisation for this indication.

It should have stated: "At the time of publication (September 2013), most botulinum toxin type A preparations did not have a UK marketing authorisation for this indication. Evidence was only available for the licensed botulinum toxin A (BOTOX, Allergan) preparation."

Cite this as: BMJ 2013;347:f6392

๑ BMJ Publishing Group Ltd 2013 